Cuadernos del CILHA n $34-2021$ | publicación continua

ISSN 1515-6125 | EISSN 1852-9615

https://revistas.uncu.edu.ar/ojs3/index.php/cilha

CC BY-NC 2.5 AR

Recibido: 22/04/2021 Aprobado: 08/06/2021 |

PP. 1-22

DOI: https://doi.org/10.48162/rev.34.007

\title{
Un piano en Bahía Desolación: trata de mujeres y pactos patriarcales en la llegada del capital y el Estado a la Patagonia
}

\author{
Libertad Demitrópulos' Un piano en bahía desolación: Women \\ Trafficking and Patriarchal Pacts in the Arrival of Capital \\ Enterprise and the National State to Patagonia
}

Florencia Abbate

https://orcid.org/0000-0002-6881-8015

Consejo Nacional de Investigaciones Científicas y Técnicas

Universidad Nacional de Buenos Aires

florencia.abbate@gmail.com

Argentina

Resumen: El artículo analiza la novela Un piano en Bahía Desolación (1994) de la escritora argentina Libertad Demitrópulos desde una perspectiva de género. El objeto principal del análisis es la protagonista femenina, Nancy, una joven inglesa de clase baja que es vendida como esposa a un ganadero austríaco de la Patagonia y trasladada en barco desde Liverpool a Punta Arenas. La hipótesis de lectura apunta a analizar la biografía del personaje como un itinerario marcado por la violencia, los pactos patriarcales y la deuda 
como mecanismo de sujeción. Esto será interpretado en relación con el episodio histórico refigurado en la novela: el encuentro entre los presidentes de Chile y Argentina en la ciudad de Punta Arenas en febrero de 1899, relacionado con la consolidación del EstadoNación argentino y la instauración de un modelo económico agroexportador. Nuestro propósito es vincular la representación de la violencia patriarcal con la instalación de la economía capitalista en la región patagónica hacia fines del siglo XIX.

Palabras clave: Demitrópulos, Mujeres, Violencia, Siglo XIX, Patagonia.

Abstract: The article analyzes the novel Un piano en Bahía Desolación (1994), by Argentine writer Libertad Demitrópulos, from a gender studies perspective. The main object of the analysis is the female protagonist, Nancy, a young lower-class English woman who is sold in marriage to an Austrian cattleman in Patagonia, and sent by boat from Liverpool to Punta Arenas. Our reading hypothesis considers the biography of the character as an itinerary marked by violence, patriarchal pacts and the use of economic debt as a restraint mechanism. This will be interpreted in relation to the historical episode staged in the novel: the meeting between the presidents of Chile and Argentina in the city of Punta Arenas in February 1899, as it sealed the consolidation of the Argentine Nation-State and the establishment of the agricultural-exporting economic model. Our goal is to link the representation of patriarchal violence with the settlement of a capitalist economy in the Patagonian region by the end of the 19th century.

Keywords: Demitrópulos, Women, Violence, $19^{\text {th }}$ Century, Patagonia.

Un piano en Bahía Desolación (1994), de Libertad Demitrópulos, transcurre en la ciudad patagónica de Punta Arenas a fines del siglo XIX y remite al momento posterior a la llamada Conquista del desierto, ya que -en su segunda parte- relata el episodio histórico conocido como "el abrazo del Estrecho", el encuentro entre el presidente argentino Julio A. Roca en su segundo mandato y el entonces presidente de Chile, Federico Errázuriz, el 15 de febrero de 1899, que expresó una política conciliatoria entre ambos países en cuanto a sus disputas por la repartición de los territorios del sur.

Se trata de una novela coral, donde las voces narrativas se van sucediendo de manera aparentemente aleatoria, y presenta tres partes bien diferenciadas: la primera transcurre en un bar del puerto de Punta Arenas y se centra en el diálogo entre Gin 
Whisky, un marino, y Nancy, la joven que toca el piano en el bar; la segunda parte gira en torno a los preparativos que ocurren en la ciudad de Punta Arenas ante la llegada del Presidente Roca; y la tercera se desarrolla en la isla Bahía Desolación y tiene como eje el encuentro entre Gin Whisky y su amigo Isidoro, un marino retirado. La novela se presenta formalmente como una composición heterogénea, que alterna registros genéricos como la novela de aventuras, el melodrama y la novela histórica, produciendo como resultado una factura completamente original, que no sigue a rajatabla las convenciones de ningún género ni proporciona un final cerrado. Estas características formales ya han sido objeto de estudio en otros dos artículos referidos a la poética de la autora y a esta novela en particular, en los que además se señala que "Ios personajes femeninos de las novelas de Demitrópulos ponen en evidencia la persistencia de la opresión que se ha ejercido sobre las mujeres de las clases populares en distintos períodos históricos" (Abbate, 2015, p. 29) y que, en Un Piano en Bahía Desolación, "el tramo narrativo dedicado a la visita de Roca a Punta Arenas parece indicar el triunfo del Estado liberal, de la generación del 80 y su proyecto de Nación, que ya sentía haber cumplido el objetivo de exterminar a los habitantes de esos espacios a los cuales los vencedores, que se apropiaron de ellos, les llamaban 'el desierto', como si allí no hubiera nadie" (Abbate, 2020, p. 318). Interesada ahora en abordarla con foco en la perspectiva de género, me interesa concentrarme en una de sus voces narrativas y personajes principales, esa joven inglesa llamada Nancy, que arriba al puerto de Punta Arenas en un barco que ha zarpado desde Liverpool.

Propongo leer la biografía de esta protagonista como un itinerario marcado por las violencias patriarcales y, específicamente, por la deuda como mecanismo de sujeción capitalista. Sostengo que sus desplazamientos de un espacio a otro pueden verse como efectos de la acción de figuras masculinas, a partir de las cuales se le impone una economía de la obediencia. A través de una red de pactos patriarcales, que rastrearé en el texto, se constituye una particular economía de la violencia basada en la deuda y en la desposesión del control del propio cuerpo. Esto será luego interpretado a la luz del contexto refigurado en la novela: la consolidación del Estado-Nación argentino y la instalación de capitales extranjeros en la región patagónica. 
2.

En la primera parte de la novela, Nancy cuenta que transcurrió su infancia como niña de una familia inglesa de clase media, progresivamente empobrecida como consecuencia de las conductas de su padre. El primer espacio es entonces el hogar y la primera figura masculina es el padre. Su madre les enseñó a tocar el piano a ella y a su hermana, que padecía tuberculosis. El padre no pudo tolerar la enfermedad de la hija y se ausentó de la casa paulatinamente, mientras se entregaba al alcohol: "Dejó de llevar la mensualidad a casa porque se bebía todo el dinero" (p. 15). La figura paterna que la novela construye es la de un hombre impotente, que no logra cumplir su función en la familia patriarcal, la de sostén económico, y se pierde en la bebida y el enojo ante la debilidad de esa hija enferma, hasta incurrir en actos leves de violencia: “Cuando mamá pedía para los remedios de la enferma, el padre se llegaba hasta el lecho y le quitaba las cobijas renegando. ¿Será posible, Jack, tanta crueldad?, decía mamá abriendo sus grandes ojos y echando un chal sobre los hombros de Rachel. Jack, querido, ¿qué está pasando entre nosotros?" (Demitrópulos, 1994, p. 15).

La ausencia del padre se extiende hasta abandonarlas por completo. Rachel, su hermana, muere finalmente de tuberculosis, en brazos de su madre. La miseria las persigue hasta el punto en que ya no pueden pagar el alquiler de la casa y deben mudarse a otra en un barrio pobre de Liverpool. La madre comienza a prostituirse, sin decírselo a su hija. Y luego el padre muere de cirrosis en un hospital, dejándoles deudas. Es entonces cuando Nancy, que acaba de cumplir dieciocho años, debe dejar el espacio de la casa y el piano y salir a buscar trabajo en una fábrica. Para pagar las deudas legadas por su padre, deberá realizar jornadas de doce horas en una hilandería. De allí surge la segunda figura masculina, el capataz de la fábrica, quien la introduce en las fiestas de un millonario llamado míster Sullivan. Será este hombre quien un día, en una de esas fiestas, mientras la protagonista yace semidormida en una habitación, la viola aquella noche y toda la mañana siguiente.

Esa tercera figura masculina, la de míster Sullivan, representa el inicio de la violencia sexual que signará la vida de la protagonista, así como el primer eslabón del pacto patriarcal que desencadenará su siguiente desplazamiento. Este nuevo desplazamiento espacial no será ya simplemente de la casa a la fábrica, sino de un continente a otro. El 
millonario convence a la madre de Nancy de que tiene una gran oportunidad para su hija, y le presenta a su socio, un "amigo importante" (p. 19): míster Thomas Lynn. Esta cuarta figura masculina es un "fuerte empresario de América del Sur" (p. 19), quien funciona como enlace en una red de trata, ya que se encarga de proveer a terratenientes de la Patagonia interesados en adquirir mujeres inglesas como esposas. Sullivan le asegura a Nancy que en las tierras del sur podría labrarse un porvenir "al lado de otro caballero que le diera su apellido, hijos y una posición desahogada" (p. 23). De este modo se produce aquello que en el negocio de la trata se llama "la captación" realizada con distintos grados de engaño-, que se vale de la situación de vulnerabilidad generada por la pobreza, y de la falta de oportunidades laborales que implicaba en sí misma la pertenencia al sexo femenino:

La cuestión era tener fe en los trámites que realizaría míster Thomas ante las autoridades y la reina Victoria, a fin de que ella y otras muchachas pudiesen viajar e iniciar una vida sin sobresaltos, en plenitud. En Liverpool, ¿qué destino le aguardaba? Eran tiempos difíciles para cualquiera, más para las mujeres solas. Consumirse en una fábrica, caer en la prostitución o llenarse de hijos y pobreza. Esas eran sus únicas salidas aunque la reina dijera que velaba por la virtud y el porvenir de las mujeres. (p. 20)

Apenas arriba al puerto de Punta Arenas, Nancy descubre que ha sido engañada y que en realidad fue vendida, a cambio de unas cuantas libras esterlinas, a un brutal ganadero de origen austríaco, que ya antes ha comprado a otra mujer, de quien se dice que murió -misteriosamente- de tristeza. Esta quinta figura masculina, Casimiro, la convierte en su esposa y la obliga a trabajar como mano de obra en su criadero de ovejas y chanchos, además de encargarse de todos los quehaceres domésticos y satisfacerlo sexualmente. Con la figura del ganadero se cierra la red de pactos patriarcales involucrados en el negocio del tráfico de mujeres, y la novela visibiliza así el tema del matrimonio forzado como un método de captación que constituye una forma de esclavitud sexual y laboral.

El testigo de esa esclavitud es la sexta figura masculina en el itinerario de Nancy: el peón del ganadero austríaco. Noche a noche, Nancy es violada por su esposo violento mientras el peón contempla: “El día que por cuestiones de trabajo más me golpeaba, a 
la noche mi marido más brutalmente me poseía. El peón, que dormía en el suelo, cerca de la asquerosa cama, presenciaba esas escenas aunque fingía dormir" (p. 33). El carácter esclavo de su relación con Casimiro queda explicitado cuando la protagonista compara su situación con la del peón y constata que, en su caso, no existe relación asalariada:

Diariamente me preguntaba cuál era el pecado cometido para merecer ese castigo. Hasta que fui viendo claro: había nacido mujer. Miraba al peón y encontraba que el infeliz, con todas sus desgracias, estaba sin embargo un escalón por arriba de mí. Casimiro, mi marido, ya fuera debiéndole o pagándole, tenía con el peón un contrato de servicios y como quiera que fuese lo respetaba y prometía pagarle (p. 33).

Por su condición de mujer, lo que rige no es un contrato laboral sino lo que Carol Pateman (1995) ha llamado "el contrato sexual", porque en el patriarcado moderno los que nacen libres e iguales son los varones, los ciudadanos, y será esta "fraternidad de hermanos" -que se distingue del anterior reinado de "los padres", el antiguo patriarcado- la que ayudará a velar la sujeción de las mujeres. Solo los varones están dotados de los atributos y las capacidades para contratar, solo los varones pueden definirse como individuos. De esta manera, el contrato social instituye la sociedad moderna como civil y patriarcal, la cual pasa a dividirse en dos esferas separadas y opuestas: el ámbito (civil) público de los varones libres e iguales, que se regirá por la ley civil; y el ámbito (natural) privado, lugar de pertenencia de las mujeres, que se caracteriza por la arbitrariedad y la subordinación al varón:

Dentro de este marco de sentido, hacer visible la historia del contrato sexual permite exponer cómo la conversión de la diferencia sexual en desigualdad política y social- es un punto fundamental de la sociedad civil moderna. Ahora el contrato muestra sus dos caras: el contrato social como historia de libertad de los varones-y el contrato sexual como historia de sujeción -de las mujeres". (Smiragalia, 2015, p. 40)

A este tema volveré más adelante, pero cabe destacar que la narradora encuentra la explicación de su terrible destino en la diferencia sexual: había nacido mujer. Como figura masculina, el peón también es parte de los pactos patriarcales, "fraternos", entre 
varones que se aseguran el acceso al cuerpo de las mujeres. Y será parte también de la lógica de la deuda: el de los hombres es un mundo de deudas que deben cobrarse, y las mujeres pertenecen al reino -no público- de las endeudadas. El peón asesina a Casimiro porque éste lo despide sin pagarle su salario, pero allí no termina su rol en la trama, ya que luego se presentará ante Nancy, a quien hace responsable de la deuda, como ya venía advirtiéndole desde páginas antes: “Vea, Miss, no quisiera ofenderla, no lo tome a mal, pero su marido, por el gusto de traerla a usted, me está debiendo mi paga que ya está atrasada en varios meses, sabe? Y yo no he venido aquí sólo por casa y comida, qué mierda" (p. 26). Tras matar al patrón, el peón va entonces en busca de Nancy, entra en el cuarto y le dice: "Vengo a que me pague" (p. 34). El relato de la protagonista refuerza e insiste en el tema de la deuda: "Se acordaba de pequeñas cosas, discusiones terribles, insultos, palizas como aquella que el austríaco me dio con la hebilla del cinto y él vino y me trajo un unto asqueroso y hediondo diciendo que calmaba el dolor y era cicatrizante"; el peón le recuerda que él se fue a caballo hasta el monte para encontrar el yuyo: “con el que le hice el bálsamo y usted se curó" (p. 35). En esta escena la coloca doblemente en deuda: por un lado, porque la hace responsable del pago que le debe su patrón, y por otro, porque es deudora por la ayuda que le dio cuando estaba lastimada. "Vino a Punta Arenas a cobrarse conmigo una supuesta deuda" (p. 41), afirma Nancy al relatar el momento en que el peón le pone el cuchillo en la garganta y ella debe desvestirse y dejarse violar.

Siguiendo a Pateman, en la base de las sociedades patriarcales ha habido siempre un pacto anterior al que hasta ahora se creía que fundaba las sociedades humanas, el "contrato social" de Rousseau. El pacto previo era el contrato sexual, que consiste en un pacto no pacífico entre hombres heterosexuales para distribuirse el acceso al cuerpo femenino. Esa rivalidad entre varones, de la que el mayor botín son las mujeres, queda también manifestada en la novela cuando el peón compara su potencia sexual con la de Casimiro: "La tiene secuestrada a la gringa en la serranía y la coge como macarrón viejo. Asco le daba por las noches sentir que el gringo tenía que trajinar como un desaforado en la cama, mientras él debía estar en el suelo escuchando. Bien hecho lo que le ha pasado" (p. 39). De esta manera, el peón reivindica el estatus de su masculinidad por sobre el de su patrón. 
Por lo demás, es el asesinato de Casimiro en manos del peón lo que habrá de ocasionar las próximas deudas de Nancy y su siguiente desplazamiento. Días después de que el peón la viola, la justicia comienza a buscarla por la muerte de su marido, sospechando de ella. La justicia la revictimiza y los poderes estatales le dejan sin dinero. Nancy vende todo lo que le quedó de Casimiro, pero casi no le sobra nada porque debe pagar abogados, impuestos, y además las deudas que el austríaco dejó. Lo último que tiene lo gasta en el hotel en el que debe refugiarse para huir de la persecución de la justicia. El crimen lo comete el peón, pero la que debe huir es ella, para evitar pagar también por un crimen ajeno. "De nuevo el hambre y la inseguridad" (p. 43), afirma; necesitaba trabajar y "solo encontraba hombres que querían acostarse conmigo" (p. 43), hasta que comprende que la única salida es prostituirse: "Me vi obligada a hacer la calle" (p. 43). Como sostuve al principio, la trayectoria biográfica de Nancy está signada por la deuda como mecanismo de sujeción patriarcal. Pero se trata también de un mecanismo de sujeción capitalista, ya que a través de la misma queda estructurada la relación acreedor-deudor como constitutiva del capitalismo. Sostiene Nancy: "Mi problema era conseguir dinero. Siempre dinero para pagar mis deudas" (p. 43). La deuda ha sido históricamente -y sigue siendo- un mecanismo de desposesión generalizado, no sólo en los casos de víctimas de trata, sino más ampliamente de poblaciones migrantes y sujetas al fenómeno de feminización de la pobreza; y es también la deuda lo que a menudo sostiene la dependencia a relaciones violentas. En esta novela, las deudas cargadas a cuenta de las mujeres deben pagarse con sexo. El crimen cometido por el peón la obliga a desplazarse de la casa al hotel, y luego a "hacer la calle".

Sin embargo, Nancy se diferencia de otras prostitutas por el hecho de que odia el sexo. Por eso no la quieren en ningún prostíbulo y solo puede acceder a los peores clientes: "Pequeños comerciantes de madera, despachantes de aduana que querían arreglarme con alguna mercadería robada, changarines del puerto, piojosos y pobretes a quienes les costaba largar un peso" (p. 43). La novela la presenta como una prostituta "poco deseable" para los clientes, ya que aborrece a los hombres y es frígida: "Nancy La Frígida me llaman desde entonces en este maldito puerto donde la suerte me trajo. $Y$ en eso tienen razón: no siento nada cuando estoy con ellos" (p. 44). La frigidez aparece como uno de los síntomas-efectos del proceso de desposesión del propio cuerpo, al que la han sometido a través de los pactos patriarcales. 
El clímax del proceso de desposesión que atraviesa la protagonista llega con su intento de suicidio, al intentar arrojarse al mar. Es allí cuando la rescata una figura masculina que, no obstante, ha abdicado del estatus de la masculinidad patriarcal y cumple una función de ruptura respecto del pacto entre varones. Se trata de un joven homosexual, Bernardino Balmaceda, quien se identifica y solidariza con Nancy por haber sufrido él mismo la violencia patriarcal, cuando tuvo que huir de su pueblo tras haber recibido palizas y amenazas por su orientación sexual:

Para escándalo de sus hermanas y de la población, se hizo de una amistad masculina. Dios los cría y ellos se juntan, sí señor, así empiezan a andar como perros, uno oliendo al otro, y ¿qué más? (...) El vecindario se alborotó y fue suficiente. La familia del amigo tomó cartas en el asunto y con un puñal en la espalda vienen y lo meten en un vehículo, le dan una tunda soberana y lo llevan a Valparaíso (...) Allí lo dejan bajo la amenaza de que si asomaba el hocico por el pueblo lo revolcarían a puñetazos: "los Mendieta somos bien machos y antes de matarte, cabronazo, te vamos a capar". (p. 51)

Bernadino trepa entonces a un barco que hacía viajes al Estrecho de Magallanes viniendo de Europa, y llega a Punta Arenas, donde instala un bar. Tras evitar el suicidio de Nancy, le propone que empiece a trabajar en su bar, tocando el piano. Bernardino es el único que le paga por hacer aquello que a ella le gusta, lo que su madre le enseñó; y la música aparece así como una forma de revinculación con la figura materna y con su lugar de origen, Inglaterra, de donde la aislaron y adonde añora regresar.

El nombre que Bernardino le ha puesto al bar es "El Hermafrodita". Este espacio aparece como una suerte de locus amoenus, en el sentido de que parece ser el único lugar de la ciudad que no se rige por las leyes patriarcales. El sitio funciona para Nancy como un genuino refugio, y la relación con Bernardino le proporciona algo que nunca había tenido, un amigo:

Hermano con hermana, en avenencia, en mutuo descubrimiento. A las quejas Bernardino le hizo sentir también que algunos hombres pagan su cuota de incomprensión, que él tuvo que abandonar todo y marcharse al sur, lejos de la ciudad que lo marcó. Se abrió camino libremente, puso un bar distinto de los 
otros, sin rameras ni borrachería, un bar donde ella entró a tocar el piano como única atracción y sólo para soñar. (p. 54)

A la fraternidad entre varones, piedra basal de la complicidad que funda la opresión patriarcal moderna, se opone aquí la fraternidad entre víctimas, que dejan de ser víctimas desde el momento en que afirman su voluntad de construir su propia vida, su capacidad de habilitar un espacio que no obedece ya a las leyes de los otros sino a sus propias leyes, es decir: su autonomía.

Pero una nueva figura masculina en la vida de Nancy acabará por romper ese orden. El protagonista principal de la novela, un marino y lobero llamado Gin Whisky, escucha la música del piano que Nancy toca y entra al bar. El primer capítulo de Un Piano en Bahía Desolación reconstruye, mediante sucesivas analepsis, el pasado biográfico de los tres personajes: Nancy, Bernardino y Gin Whisky, luego de que éste ingresa al bar. El marino intenta seducirla y dialoga con ella, escucha su historia y le cuenta la suya, que se centra en sus aventuras por los mares con su amigo Isidoro y otros marinos, relatadas con tópicos de género de la novela de aventuras, y con ecos intertextuales de los relatos en los mares del sur de Jack London. Hacia el final del relato del pasado de Gin Whishy, Isidoro se retira de los viajes y deja en su reemplazo a un marinero holandés llamado Joris, de quien Gin Whisky desconfía y luego culpabiliza por el naufragio de su barco, que ocurre por entonces. Cuando se retoma la línea temporal del relato primario -una vez que Nancy y Gin Whisky se han contado sus respectivas biografías-, nada sucede entre ellos. Gin Whisky ha fracasado en su intento de conquistar a Nancy. Ella lo rechaza y lo considera un hombre más; piensa que Bernadino la protege, en cambio "Gin Whisky era un hombre de mar, uno de esos que van a las mujeres sólo por el sexo y después se iban" (p. 46). En el segundo capítulo es Joris quien ingresa al bar El hermafrodita y se acerca a Nancy pretendiendo conquistarla, pero Bernardino lo echa. Joris regresa, llena una copa con oro -como si demostrara también el estatus de su masculinidad a través del poder que simboliza el dinero- y así consigue conversar con la protagonista y seducirla. A las tres de la mañana, Nancy y Joris parten juntos a la casa de ella. A continuación, Gin Whisky se dirige a la casa de Nancy, irrumpe en aquel encuentro íntimo, los ve semidesnudos en la cama, y asesina al holandés. Nancy, quien por primera en su vida ha tenido un encuentro sexual placentero, presencia el asesinato del único hombre a quien ella se entregó por propia voluntad. 
Lo curioso es que dicha resolución extrema de la rivalidad entre ambos marinos, sólo se vale de Nancy como excusa, ya que esconde su motivo profundo, el verdadero amor de Gin Whisky: su amigo Isidoro. Ese amor reprimido, que existe poderosamente al margen de los encuentros sexuales de Gin Whisky con prostitutas, es lo que motiva el episodio central de la tercera parte, cuando el marino se dirige a Bahía Desolación, a reencontrarse con Isidoro y a intentar hablar con él -por primera vez explícitamentedel amor que los unió. Es notable que aquí, otra vez, la mujer es tan sólo un botín de la disputa por el poder entre varones, dado que Gin Whisky no asesina a Joris por amor a Nancy, sino más bien para demostrar su superioridad por sobre otro varón que logró acceder a un cuerpo al que él no pudo acceder. Una motivación similar a la del peón cuando la viola tras haber tenido que presenciar los actos sexuales de Casimiro. En sintonía con las ideas de Segato (2003), la novela de Demitrópulos parece presentar el acto de violación, no como una forma de satisfacción de la libido sexual, sino en todo caso como un crimen de razón expresiva, que busca anunciar la masculinidad: esa potencia que no existe si no se espectaculariza. Uno de los ejes de la violación, para Segato, es que el violador desea exhibir su poder como varón frente a otros varones significativos para él. Así, el asesinato de Joris puede ser leído como una forma de espectacularización de la masculinidad de Gin Whisky, quien necesita demostrar su estatus ante Joris e Isidoro. El mandato de la masculinidad exige gestos extremos, incluso el de aniquilar a otro ser para sentirse potente:

El estatus masculino, como lo demuestran en un tiempo filogenético los rituales de iniciación de los hombres y las formas tradicionales de acceso a él, debe conquistarse por medio de pruebas y la superación de desafíos que, muchas veces, exigen incluso contemplar la posibilidad de la muerte. Como este estatus se adquiere, se conquista, existe el riesgo constante de perderlo y, por lo tanto, es preciso asegurarlo y restaurarlo diariamente. Si el lenguaje de la femineidad es un lenguaje performativo, dramático, el de la masculinidad es un lenguaje violento de conquista y preservación activa de un valor. La violación debe comprenderse en el marco de esta diferencia y como movimiento de restauración de un estatus siempre a punto de perderse e instaurado, a su vez, a expensas y en desmedro de otro, femenino, de cuya subordinación se vuelve dependiente. (Segato, 2003, p. 38) 
Gin Whisky es entonces la séptima figura masculina que interviene en el itinerario de Nancy y ocasiona un nuevo desplazamiento. Al igual que ocurrió cuando el peón mató al ganadero, aquí el crimen lo comete Gin Whisky pero la que debe huir es ella. No obstante, a diferencia de los anteriores, esta vez se tratará de un desplazamiento deseado, puesto que es Bernardino quien funciona como enlace en esta ruta. Anticipando que las autoridades convertirán a Nancy en responsable del asesinato de Joris, quien yace muerto en casa de ella, Bernardino decide ayudar a Gin Whisky a deshacerse del cadáver y juntos proceden a enterrarlo. De este modo, Bernardino libera a la protagonista de lo que se avecina como su próxima deuda -tener que pagar por un crimen que no cometió, tal como debió pagar por las deudas de su padre y luego de Casimiro- y en ese acto interrumpe lo que podríamos llamar la cadena de las deudas en la ruta de la desposesión.

Bernardino convence a Gin Whisky de que debe entregarles su dinero para que Nancy pueda tomar un barco de regreso a Liverpool, y él se irá con ella. El marino, que sustenta una ética del riesgo y la aventura -opuesta a la lógica económica que intenta instalar el incipiente capitalismo en la región-, accede a desprenderse de su dinero y les brinda así la llave que posibilita la fuga. Aunque la misma no sea, en realidad, paradójicamente, sino un regreso, el retorno a Liverpool, como un círculo perfecto, que habrá de devolver a la protagonista al lugar del que partió. Bernardino convierte la desgracia en posibilidad. ¿Qué ocurre con Nancy a su regreso? No lo sabemos, pues hay una elipsis. La novela, como anticipé al principio, deja un final abierto.

\section{3}

Si la primera parte se centra en la vida de Nancy -narrada en un registro genérico cercano al melodrama-, la segunda está enfocada en el contexto político-social, e incluye elementos de datación y reconstrucción histórica. Las referencias aluden a la visita del Presidente Roca y a la "fiebre del oro" que acompañó las campañas de exterminio de indígenas; también, al auge de empresas de prestamistas ingleses en la ciudad, a la caída en desgracia de la actividad de los marinos -que ya no tienen un lugar importante en la nueva economía-, y a los pactos y negocios entre el Estado y los colonos europeos que habrían de convertirse en los grandes terratenientes ganaderos de la región patagónica. 
En este sentido, cabe mencionar que la segunda parte incluye como historia secundaria los periplos de un personaje histórico, Julio Popper, ingeniero rumano y expedicionario, uno de los primeros que cartografiaron la región y fueron testigos y/o artífices del genocidio indígena. Popper arribó a Tierra del Fuego en 1886, donde descubrió el más importante yacimiento aurífero en territorios australes. De regreso a Buenos Aires en 1887 concretó una negociación que le permitió volver a la Patagonia con los papeles que lo habilitaban para explotar todos los yacimientos que encontrara -la novela consigna que "hasta llegó a retar a duelo al gobernador de Punta Arenas por un asunto de identificación nacional” (Demitrópulos, 1993, p. 131).

La historia de Nancy ya no vuelve a aparecer en primer plano en la segunda parte, excepto cuando ella y Bernardino suben al barco rumbo a Liverpool. Sin embargo, algunos elementos concernientes a su historia reaparecen de manera inconexa, como si fueran indicios que la autora va dejando para comprender la dimensión social de su caso individual, el marco histórico en el que debe interpretarse su atribulada biografía. En este sentido, un personaje secundario que tiene un papel destacable en la segunda parte es el Sargento Epifanio, presente por ejemplo cuando, realizando tareas de limpieza en la ciudad para recibir a los presidentes de Chile y Argentina, empleados de la gobernación descubren casualmente el cuerpo enterrado del holandés:

El cadáver de Joris apareció inesperadamente debajo de las palas limpiadoras de nieve, lo que fue considerado un trabajo extra para las autoridades competentes. Con tanto trajín debían ocuparse de la identificación de la víctima [...] Entonces el sargento Epifanio pidió autorización para investigar, de paso que hacía su trabajo en los bajos fondos y en el puerto. (p. 109)

La corrupción del sargento también aparece mencionada en referencia al tráfico de mujeres, en relación al cual su silencio revela que las fuerzas institucionales también forman parte de los pactos patriarcales que implica el negocio de la trata:

Hoy el puerto es para que el gordo trabaje con tranquilidad, y la misión del sargento Epifanio es garantizar esa tranquilidad. El sargento sabe muy bien quién es el gordo. De qué se ocupa [...] Es una cosa rejodida la venta de mujeres y a él no le va en nada, pero la orden es dejar trabajar al gordo y hacer la vista también gorda. Por eso cuando alguna chibola se retoba y llama a la policía, 
police, él sabe hacerse el desentendido, mirar los papeles como si estuvieran en orden y quitar toda esperanza a la mujer. (p. 113)

Bien recuerda Epifanio a aquella gringa rubia que hace tres meses se emperró como ninguna y lo buscó y lo encontró para que la protegiera del vejete mugriento y pedía justicia gesticulando y discutiendo, y él, re pencas, se quedó tan pancho, distraido, haciendo como que no entendía el idioma cuando sabía que a lo mejor a la pobre mina la esperaba el infierno. (p. 115)

El pacto patriarcal se presenta como el reconocimiento inmediato y la identificación de un hombre con otro hombre, interactuando en un idioma privilegiado y desconociendo cualquier empatía con la mujer. De alguna manera, se trata de una actitud no tan distinta a la asumida por Gin Whisky cuando Nancy le cuenta lo que sufrió con su esposo y él le da una respuesta que parece justificar la violencia, ya que quiere explicarle: "Que Casimiro, perdido allá en las serranías, tenía necesidad de una mujer, dentro de su brutalidad quiso acercarse al amor. [...] La necesitaba como compañera y personificación de sus ideales aunque, al mismo tiempo, por su formación, era autoritario y se expresaba a los golpes" (p. 55). Ningún personaje masculino, excepto Bernardino, siente ninguna empatía con la situación de Nancy, cuya vida ha sido literalmente vendida. De este modo la novela escenifica de múltiples maneras esa complicidad corporativa masculina que Pateman investigó y pensó en términos de un pacto fundante del régimen político moderno, organizado sobre el pilar la subordinación de las mujeres y los cuerpos feminizados -como Bernardino. Por otra parte, ese régimen político moderno, en la novela, remite a la presidencia de Roca y aparece vinculado a la violencia fundante del exterminio indígena. En un extraordinario pasaje de esta segunda parte se relata que, mientras los presidentes realizaban su célebre abrazo: "Los cazadores de hombres aprovechaban la ocasión para rematar orejas de onas, a una libra el par, que los hacendados pagaban gustosos" (p. 110).

Recordemos que, hacia 1890, en aquella región "tanto las tierras como el comercio, el crédito y el transporte eran controlados, a ambos lados de una delimitación internacional todavía no materializada, por europeos establecidos poco más de una década antes en Punta Arenas y rápidamente articulados, mediante redes de corrupción, con las oligarquías de Buenos Aires y Santiago" (Harambour, 2017, p. 553). Con Punta Arenas como centro, y gracias al apoyo del Estado chileno, primero, y del 
argentino, después, dentro de un proceso mundial de expansión imperial y nacional, "el capital llegó hasta las profundidades de la estepa en la forma de ovejas" (p. 595). En tal sentido, agrega Harambour, el Abrazo del Estrecho "es célebre por cuanto selló la paz, amenazada por la carrera armamentista, pero su mayor efecto político fue acrecentar el poder de la oligarquía local. El presidente chileno Federico Errázuriz, conducido por una escuadra comandada por el exgobernador Manuel Señoret, almorzó en el palacio de Sara Braun a su llegada a puerto; Julio Argentino Roca, por su parte, durmió en el palacio de José Menéndez luego de la gala que le ofrecieran los comerciantes en la gobernación, donde oficiaron como 'dueñas de casa' Sara y su cuñada, Josefina Menéndez. Al día siguiente, Julio Roca, sus ministros de Marina y Relaciones Exteriores y algunos diputados almorzaron en el mismo palacio. Entonces, recordaba Braun, fueron invitados 'para que pobláramos y abriéramos nuestro comercio e industria en la Patagonia, asegurándonos el total favor de su Gobierno'" (p. 582). Así, aquel encuentro entre presidentes también decidió la expansión de los capitales representados por Menéndez y Braun, desde Punta Arenas, sobre la Patagonia argentina, convirtiéndola en un gran "vivero de lana para Inglaterra", como Karl Marx definió a Australia. Harambour propone que el capital europeo y los Estados nacionales se constituyeron recíprocamente y que su articulación como forma de soberanía conjunta, pero identificables (la soberanía del capital y la soberanía estatal) se produjo en torno a la conversión del espacio vaciado de indios/as en tierras de pastoreo de ovejas, así como a la corrupción y el tráfico de favores.

Esta somera reconstrucción del significado político del episodio histórico relatado en la novela (el Abrazo del Estrecho), viene a cuento porque permite plantear que los personajes de Casimiro y Gin Whisky representan dos polos de una tensión económica. El ganadero austríaco que compra y secuestra a Nancy, un criador de ovejas, representa el nuevo orden económico que el Estado promovió. El lobero Gin Whisky, por su parte, encarna lo que está siendo derrotado con la llegada del capital y del Estado a la región, un espíritu nómade y ajeno a la sed de acumulación capitalista, incluso una ética romántica, de marineros que han sabido ser amigos de las tribus indígenas, con quienes compartían algunas formas de vida. Las aventuras relatadas por Gin Whisky muestran esa amistad: "Desde lejos, Usiniaga el indio yagan nos hacía señas, había reconocido el cúter y venía a toda velocidad a nuestro encuentro en una canoa manejada por su mujer [...] Usiniaga me esperaba porque también iba a participar de la expedición. Participaba

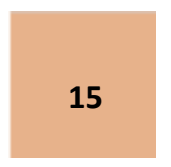

Cuadernos del CILHA n $34-2021$

ISSN 1515-6125 | EISSN 1852-9615 
por orgullo físico, no por interés, ya que no tenía desarrollado el sentido del dinero ni el valor del oro" (Demitrópulos, 1993, p. 59).

En la segunda parte de la novela, Gin Whisky se cruza a Julio Popper cuando acude a la oficina del más importante prestamista extranjero de la ciudad para pedirle que le financie una nueva salida al mar. Pero el trato se ve frustrado porque este hombre, representante del nuevo orden económico, le exige que a cambio traslade mercadería ilegal a la Argentina. Ofendido, Gin Whisky responde: “¿Contrabando? ¡Están locos! ¿Qué se han creído? Soy lobero, no contrabandista. La plata me la gano trabajando" ( $p$. 136). Parece claro que en el nuevo orden económico son los ganaderos y los corruptos los que han triunfado. $Y$, por ello, consciente de que los sedentarios derrotaron a los nómades, y de que ha llegado a su fin todo un mundo repleto de vidas que no se identifican con el Estado, el dinero ni el poder, Gin Whisky decide zarpar rumbo a la isla Bahía Desolación, donde se ha recluido su amigo Isidoro, para olvidar su pasado.

Isidoro, personaje central de la tercera parte, nació en Buenos Aires pero ha decidido abandonar la cultura occidental, para vivir en una temporalidad por fuera de la Historia, vinculada a la cosmovisión que le trasmiten las mujeres de la comunidad de Bahía Desolación: "Aprendo de estas indias el verdadero valor de las cosas y a prescindir de lo superfluo. Ellas no saben el bien que me hacen. He perdido la cuenta de los días como mis esposas, que viven fuera del tiempo" (p. 161). La tercera parte, que transcurre en Bahía Desolación, ese espacio "sin tiempo", establece un contraste con la segunda, que ponía en primer plano el tiempo histórico al incluir elementos de datación y reconstruir el contexto político. Bahía Desolación "es un espacio que se resiste a ser colonizado por el tiempo y por la idea de progreso que conlleva el proyecto de Nación" (Abbate, 2020, p. 320). Isidoro se presenta como un personaje desencantado de la modernidad, que reniega de ella y prefiere a las tribus, porque considera que la verdadera barbarie es la civilización. Vive entonces rodeado de mujeres indígenas, ajenas al proceso que comandaban esos pactos entre el Estado y los colonos e inversionistas europeos: la recodificación de la tierra, de los territorios, pero también de los cuerpos de las mujeres, como propiedad privada.

Hacia el final de la tercera parte, un barco de loberos que se dirigía a las islas Malvinas atraca en la caleta. Han debido detenerse porque parte de la tripulación, incluyendo al 
capitán, delira de fiebre. En ese barco se marcha Gin Whisky de Bahía Desolación, luego de no haber logrado conversar con Isidoro de ese amor que los unió: "Todo lo que vengo diciendo desde que llegué a Desolación era hablado de la boca para afuera, callándome lo de adentro, todo eso eran rodeos para eludir lo principal que es la muerte de Joris y cierta cosa que hubo (o hay) entre nosotros y que está sin aclarar" (Demitrópulos, 1993, p. 167). Pero Isidoro no está interesado en hablar eso que hubo entre ellos, y le responde: "Tampoco tengo, como sospechas, ningún nudo que desatar. El nudo ya fue desatado cuando me vine a Desolación. Lo tuve, sí, y me asfixiaba, cuando estando a tu lado no te diste cuenta. Ahora, ¿qué remediaríamos con volver atrás? (...) Precisamente porque nunca pasó nada, porque nunca coincidieron nuestros tiempos, es que me separé y quise venir aquí (pp. 172-173). Tras ese diálogo, Gin Whisky se marcha de la bahía, pero la fiebre queda. Es el síntoma de la peste que trajeron los hombres blancos y se le ha contagiado a la comunidad, provocando la muerte de su población. Lo último que quedaba del orden anterior a la llegada del capital y el Estado se extingue a causa de la "fiebre amarilla". Y el barco en el que viaja Gin Whisky se encamina hacia su destrucción, puesto que la presencia de un iceberg sugiere su posterior naufragio. Como una alegoría del hundimiento del orden anterior a la llegada del capital y el Estado.

\section{4}

Ahora bien, ¿qué lugar tiene la historia de Nancy en esta refiguración del momento de consolidación del Estado-Nación argentino y del proyecto de la Generación del 80, con la figura de Roca como símbolo? En primer lugar, como ya anticipé, la novela parece poner en evidencia la raigambre patriarcal que la cultura moderna no "supera" sino que incorpora en su matriz, el contrato sexual. En palabras de Pateman:

Narrar la historia del contrato sexual es mostrar cómo la diferencia sexual, qué es ser 'hombre' o 'mujer', y la construcción de la diferencia sexual como diferencia política, es un punto central para la sociedad civil [...] En el patriarcado moderno, la diferencia entre los sexos se presenta como la quintaesencia de la diferencia natural. El derecho patriarcal de los varones sobre las mujeres se presenta como el reflejo del propio orden de la naturaleza. (1995, p. 28) 
La esfera del contrato y la del estatus coexisten, como argumenta Pateman, ya que son dos universos de sentido que, a pesar de tener raíces en tiempos diferentes, se amalgaman; no hay ruptura sino continuidad. El estatus introduce una suerte de inconsistencia en la modernidad, pero ese elemento inconsistente, según Segato, obedece a una historia de larguísima duración y gran resistencia al cambio: "El primero rige las relaciones entre categorías sociales o individuos que se clasifican como pares o semejantes. El segundo ordena las relaciones entre categorías que, como el género, exhiben marcas de estatus diferenciados, señas clasificatorias que expresan un diferencial de valor en un mundo jerárquico. Estas marcas son construidas y percibidas como indelebles" (Segato, 2003, p. 253). En esta línea, cabe destacar que la novela de Demitrópulos elude el riesgo de idealizar las relaciones entre varones y mujeres anteriores al capitalismo. Lo que muestra es más bien que el mundo moderno incorporó la matriz patriarcal que ya existía, y que la promesa de igualdad, libertad y fraternidad no abarcó a las mujeres. No sólo las figuras masculinas involucradas en el negocio de la compra-venta de Nancy (Sullivan, Thomas, Casimiro), sino también los marinos, que encarnan una ética distinta a la de estos capitalistas, responden a la lógica del estatus de la masculinidad que se afirma en detrimento del cuerpo, la vida, la igualdad y la libertad de la mujer. Así, por ejemplo, Gin Whisky acepta como ciertas las palabras de otro marino, el Chato: “¿Sabe lo que dice el Chato? Amar a una mujer es como dar la paliza a los lobos: sigilosamente, mientras duermen bajo el sol caerles desde lo alto hasta la playa donde retozan y empezar a golpear sus cabezas antes de que los lobos se despierten y te arrastren con ellos al mar" (Demitrópulos, 1993, p. 28). Asimismo, la novela evita idealizar la situación de las mujeres indígenas representadas en la tercera parte; tampoco ellas provienen de un mundo donde hayan sido tratadas como iguales. Cuando Isidoro le cuenta a Gin Whisky que ha tenido diez hijos con las indígenas, afirma que son ardientes y que, si bien no tienen la coquetería de las blancas, poseen sus propias virtudes: "Cada una es una mina de oro para el marido, el sostén de hogar y la mano de obra obligada. En sus tribus están dominadas por sociedades masculinas de carácter secreto donde ellas no tienen acceso ni voz ni nada" (p. 156).

El itinerario de Nancy la coloca como objeto de una escena en la que, una y otra vez, se vuelve un botín de los negocios o rivalidades entre hombres: Entre el capataz de la fábrica y Míster Sullivan. Entre Míster Sullivan y Míster Thomas Lynn. Entre Míster Thomas y el ganadero austríaco. Entre el ganadero austríaco y el peón. Y, finalmente,

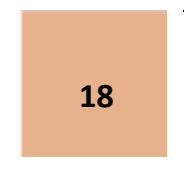

Cuadernos del CILHA n $34-2021$ 
entre Gin Whisky y Joris. Ya sea a través del matrimonio o de la prostitución, el lugar de las mujeres como objetos sexuales en ningún caso se modifica. Y en este sentido, ni los capitalistas, ni los marinos ni los indígenas parecen en esta novela exentos de esa relación con las mujeres que De Beauvoir describió como una relación donde no existe reciprocidad ni reconocimiento, sino la constitución de seres socialmente subordinados, de una Otra que no es vista como sujeto sino como objeto.

En la ficción política moderna del contrato social, las relaciones contractuales son el paradigma de las relaciones libres. Pero la fraternidad, desde el enfoque de Pateman, tiene que ver con la constitución de los hombres como maridos, trabajadores y ciudadanos, mientras que las mujeres habrían sido excluidas de dicho contrato, ya que no accederán al mundo público como individuos sino como mujeres fundamentalmente, esposas o prostitutas. El contrato sexual es entonces la parte reprimida del contrato social. El matrimonio sostiene el contrato sexual en el ámbito doméstico, y la prostitución -esa gran industria capitalista que signa la vida de Nancy y la de su madre- mostraría como en el ámbito público del derecho patriarcal se instala la demanda de los varones de que los cuerpos de las mujeres se vendan como mercancías. El contrato sexual garantiza el acceso controlado al cuerpo de las mujeres. Y la historia de Nancy parece mostrar la continuidad implícita en ese momento de transición entre el antiguo patriarcado, basado en el poder de los padres, y el nuevo patriarcado fraternal moderno.

El otro punto que me interesa resaltar es que Demitrópulos elige tomar distancia de un tópico que ha sido uno de los ejes de la representación literaria de la mujer en el siglo XIX argentino: el de la cautiva. Un tópico que tuvo un rol particular en la construcción de discursos que sirvieron a la legitimación de la política ofensiva contra los pueblos indígenas y la apropiación de territorios que estaban en su poder:

El lamento por el destino de la mujer secuestrada entre los salvajes, sometida a sus deseos sexuales y a la servidumbre, no sólo obviaba el hecho colonial inicial -la conquista llevada adelante por viajeros varones que veían en las mujeres indias piezas de caza- sino que defendía más el derecho de los hombres blancos a la propiedad -de mujeres, animales y cosas-que la libertad de las cautivas de hacer lo que quisieran. Motivo del héroe y también artilugio para el pacto: ahí,

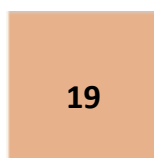

Cuadernos del CILHA n $34-2021$ 
nuestro entrañable Martín Fierro, que encuentra en la defensa de la dama violentada el motivo para retornar al orden que había abandonado por injusto. Entonces, cercar las tierras, aniquilar al indio, incorporarse al mercado mundial, todo en nombre de la cautiva liberada. (López, 2017)

Demitrópulos no escoge poner el foco en las cautivas inglesas de las tribus, sino en una cautiva inglesa del propio capitalismo, y este es, a mi entender, uno de los mayores hallazgos de esta novela leída en clave de género y en diálogo con la literatura argentina de y sobre el siglo XIX. La historia de la "captación" de Nancy es también la de una intersección entre violencia de género y violencia económica y social: mujer, joven y pobre. Cuando el Estado capitalista se consolida en Argentina y Chile, ella huye. Como si ya hubiera visto en Inglaterra que nada de eso traería libertad e igualdad para las mujeres pobres. El nuevo orden en Punta Arenas no parece ser superador del orden anterior; notablemente, antes de tomar el barco con destino a Liverpool, Nancy y Bernardino pasan por la puerta del que fuera el bar El hermafrodita y observan que: "EI nuevo patrón sacaba el antiguo cartel para colocar otro que decía El Macho, nombre que, según les dijera el hombre, era mejor que aquel raro que tenía, nombre corto, preciso, sin tantos chirimbolos y que la gente entiende lo que quiere decir (Demitrópulos, 1993, p. 117).

Ya hacia 1870, la activista feminista Josephine Butler (1828-1906) denunciaba desde Liverpool lo que se denominaba "white slave trade" (trata de blancas), en referencia a las mujeres y niñas traficadas en Europa para ser explotadas como sexoservidoras, sirvientas, esposas, esclavas, etcétera. No obstante, recién a mediados del siglo XX la trata comenzaría a ser un tema de legislación internacional, cuando en 1949 la Asamblea General de las Naciones Unidas (ONU) aprobó el Convenio para la Represión de la Trata de Personas y la Explotación de la Prostitución Ajena. Pero la impunidad no cejó puesto que, como señala Giberti: “Aunque se trató de un logro sumamente paradigmático, ello no repercutió en acciones concretas por parte de los países miembros para frenar este delito" (Giberti, 2016). Entonces, en este punto, la novela permite leer otra continuidad, relativa a la pervivencia de los mecanismos implicados en la trata de mujeres: la captación por la vía del engaño, el aislamiento del lugar de origen -lo que en muchos casos las convierte en migrantes-, el endeudamiento como medio de sujeción y violencia económica, la complicidad de los poderes institucionales

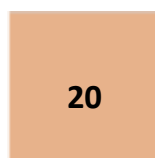


y, por supuesto, la violencia sexual. Dado que estos mecanismos siguieron siendo exactamente los mismos desde el período en que transcurre la novela hasta la década neoliberal de su año de publicación (1993), cuando aún en la Argentina existía un vacío jurídico respecto de este crimen, el fenómeno de la trata queda expuesto como una densa y compleja red de pactos patriarcales que todavía hoy está muy lejos de haberse desanudado ${ }^{1}$.

\section{Referencias}

Abbate, F. (2015). “Un piano en Bahía Desolación y algunas constantes en la obra de Libertad Demitrópulos", Hispamérica, 131, 27-25. https://www.jstor.org/stable/44504417

Abbate, F. (2020). "Las novelas de Libertad Demitrópulos: Vindicación de la forma que no llega a buen puerto", Badebec, 19, 132-149. https://revista.badebec.org/index.php/badebec/article/view/487/441

De Beauvoir, S. (1962). El segundo sexo. Siglo Veinte.

Demitrópulos, L. (1994). Un piano en Bahía Desolación. Braga.

Falquet, J. (2017). Pax neoliberalia: perspectivas feministas sobre (la reorganización de) la violencia contra las mujeres. Madreselva.

Gago, V. y Cavallero, L. (2019). Una lectura feminista de la deuda. Fundación Rosa Luxemburgo.

Giberti, E. (2016). La trata de personas. Revista Diagnosis, 13.

https://www.revistadiagnosis.org.ar/index.php/diagnosis/article/view/62

\footnotetext{
${ }^{1}$ Sostiene Giberti: “En la perspectiva mundial la trata está ubicada en una estadística que ocupa el tercer lugar de delitos luego del tráfico de armas y el de drogas. Los organismos internacionales que se ocupan del tema estiman que en el mundo existen 21 millones de personas esclavizadas por la trata y que el negocio mueve 32.000 millones de dólares en todo el mundo. Se conceptualizó una trata de personas con finalidad sexual prostituyente y también una trata con personas que son reclutadas para la producción de prendas de ropa o tareas domésticas o campesinas (recolectores por ejemplo). Este delito constituye una degradación de la condición de seres humanos de las víctimas y trasciende lo meramente corporal: es la 'venta' de seres humanos y la compra de sus servicios" (2016). Hasta 2008 no existían en la Argentina estadísticas oficiales. Recién el 29 de abril de 2008 se sancionó la Ley 26.364 para la Prevención y Sanción de la Trata de Personas y Asistencia a sus Víctimas, acorde a los dictámenes del protocolo internacional. A fines del 2012, a partir de las críticas que había recibido dicha ley por cuestiones como el alcance del consentimiento de la víctima mayor de dieciocho años y la falta de mecanismos de asistencia a las víctimas, fue derogada y reemplazada por la Ley 26.842, aprobada por la Cámara de Diputados a pocos días de conocerse el fallo del caso judicial por la desaparición de "Marita" Verón, en el que fueron absueltos los trece imputados.
}

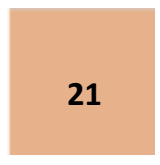

Cuadernos del CILHA n $34-2021$ 
Un piano en Bahía Desolación: trata de mujeres y pactos patriarcales en la llegada del capital y el Estado a la Patagonia

Harambour, A. R. (2017). Soberanía y corrupción. La construcción del Estado y la propiedad en Patagonia austral (Argentina y Chile, 1840-1920). Historia, 50 (2), 555-596.

https://scielo.conicyt.cl/scielo.php?script=sci arttext\&pid=S0717-71942017000200555\&lng=es\&nrm=iso

López, M. P. (2017). El femicidio de Micaela. La cautiva. Anfibia http://revistaanfibia.com/ensayo/lacautiva/

Pateman, C. (1995). El contrato sexual. Anthropos.

Segato, R. (2003). Las estructuras elementales de la violencia. Universidad Nacional de Quilmes. 